\title{
Groundwater- Surface Water Interaction, its Importance, In-situ Monitoring and Monitoring Challenges-An Overview
}

\author{
Mamatha Prabhakar* \\ Kelappaji College of Agricultural Engineering \& Technology, Kerala Agricultural University, \\ Tavanur (P.O), Kuttippuram, Kerala, India \\ *Corresponding author
}

\begin{abstract}
A B S T R A C T
Keywords

Groundwater (GW)surface water $(\mathrm{SW})$ interaction, Scales of interaction, Monitoring challenges, In-situ monitoring of GWSW interaction

Article Info

\section{Accepted:}

07 March 2020 Available Online: 10 April 2020

Groundwater-surface water interactions include the exchange of fluids and solutes between groundwater and surface water, which can affect water quality and water supply. Investigating the interaction of groundwater and surface water is essential to water managers and hydrologists for the improvement of effective waterresource policy, water resource protection and management. The effects of groundwater-surface-water exchange can occur on a variety of spatial and temporal scales. Hence, useful predictions based on point measurements are difficult because the characteristics of groundwater-surface water exchange can vary over time and across a site or region. Research into groundwater-surface water interaction has revealed many challenges on our ability to make measurements accurately as well as on appropriate scale. Despite these challenges, innovations in monitoring methods using geophysics, tracers, temperature, and remote sensing have provided new insights into spatial and temporal variation in groundwater-surface water interactions.
\end{abstract}

\section{Introduction}

Surface water (rivers, lakes, reservoirs, wetlands, oceans etc.) and groundwater interacts with each other nearly everywhere on Earth. This interaction usually takes place through the loss of surface water to groundwater, seepage of groundwater to surface water body, or a blend of both. The interactions between surface water and groundwater also include the modification of the physical, chemical, biological, and energetic properties of the water. The development or contamination of surface water or groundwater resources typically has an effect on each resource (Winter et al., 1998). So, a basic understanding of the interactions between surface water and groundwater is essential to deal with waterresource problems, for better management of water resources and sound policy making. Also, Groundwater-surface water interaction can improve our understanding of the global water cycle as the understanding the hydrologic cycle also requires knowledge on flux boundaries from one reservoir to another. 
GW-SW interactions have considerable implications for water quantity, water quality, and health of aquatic ecosystems. For instance, contaminated $\mathrm{GW}$ discharge can degrade surface water bodies and associated habitats. Over abstraction of GW can also result in the redistribution or disappearance of SW resources and the contamination of fresh water aquifers in case of coastal regions.

\section{Scales of groundwater-surface water interaction}

GW interacts with SW on a range of scales namely, large-scale interactions, where the whole catchment or watershed influences the interaction process and local-scale interactions within the hyporheic zone controlled mainly by stream-bed properties. The hyporheic zone is the region of sediment and porous space below and alongside a stream bed, where the mixing of shallow groundwater and surface water takes place.

In the case of large-scale interaction, recharge-discharge dynamics of groundwater are controlled by groundwater flow systems (on a regional and intermediate scale). Boundary conditions imposed by physiographic framework and distribution of recharge characterize the groundwater flow systems. The physiographic framework includes the topographic and geological conditions of a region, while recharge distribution is controlled by climate. Toth (1963) classified the flow systems into regional, intermediate, and local. Regionalflow systems are recharged at regional water divides and discharge into regional (higher order) streams, while local-flow systems are recharged at local water divides and discharge into local (lower order) streams. Extensive flat areas limit the development of flow systems due to low hydraulic gradients. The regional-flow systems tend to be deep, steady, slow (low flux), and more mineralized, while local-flow systems are shallow, unsteady (high variability), fast (greater flux), and less mineralized. The interaction of groundwater and surface water on regional to local scales is dependent on position of the surface water body with respect to the groundwater flow systems, anisotropy and hydraulic conductivity contrasts of the groundwater system, regional flow, Configuration of the water table and Depth of the surface-water body (Winter, 1976):

Channel interaction takes place with the water present in the underlying sediments, i.e., the sediments immediately beneath the surfacewater body. This interaction is independent of the large scale interactions. This highly localized interaction between the groundwater and surface water is superimposed on the overall gaining and losing portions of a surface-water body (Woessner, 2000). Therefore an effluent (gaining) river reach may have localized zones where stream water infiltrates the underlying sediments (Brunke and Gonser, 1997). The highly localized flow systems that develop within the sediments beneath surface-water bodies are mainly are controlled by irregularities or topography of the surface-water bed and hydraulic conductivity distribution within the underlying sediments (Woessner, 2000)

Downwelling of stream water takes place when the longitudinal bed profile of streams is convex, whereas upwelling of hyporheic as well as deeper water takes place when the longitudinal bed profile is concave (Vaux, 1968). Convexity and concavity in stream beds may be present on a range of scales and it may be related to pool and riffle sequences in high gradient streams, and also to sediment bars, dunes, and ripples.

The hyporheic zone is contains relatively high total organic carbon and microbial communities and therefore increasing the 
potential for biochemical reactions of pollutants derived from surface water or groundwater. The hyporheic zone is significant while considering surface and groundwater quality and stream ecological functions.

\section{Significance of groundwater-surface water interaction}

Groundwater-surface water interaction can play a key role in understanding both physical and chemical fluxes in the hydrologic cycle. Usually groundwater and surface water systems have commonly been studied separately, making it difficult to quantify the fluxes. In spite of that, there is increasing recognition of the importance of understanding how this interface influences hydrologic budgets, geochemical cycles, ecosystems, and global change. Zekster and Loaiciga (1993) evaluated that while about $6 \%$ of freshwater fluxes to oceans comes from groundwater as opposed to surface water, the salt loading was at least $50 \%$ from groundwater. In another study by Winter et al., (1998), in 24 regions of the United States which are delineated, groundwater contribution to stream flow ranged from 14 to $90 \%$ with a mean of $55 \%$.

Groundwater chemistry has a signature different from streams, lakes, and oceans. While groundwater is less saline than ocean water and groundwater discharge is increasingly recognized as a source of dissolved solids that impacts geochemical cycling and ecosystems disproportionately to the total fluxes. Flux from the ocean to groundwater (seawater intrusion) is a threat to freshwater supplies in coastal aquifers, which may be enhanced due to pumping and sea level rise. Geochemical fluxes across groundwater-surface water interface can provide a mechanism for spreading contamination.
Monitoring fluxes at the groundwater-surface water interface may also provide an indicator of impacts of climate change. The hydrologic cycle is likely to get alter under climate change scenarios by stronger storms and longer droughts. However, uncertainties in the hydrologic budget make prediction difficult and the different scales of climate models and hydrologic components makes assessing impacts challenging. Furthermore, land use change and climate impacts have overlapping and potentially amplifying effects. These issues highlight the importance of improving our understanding of fluxes across the groundwater-surface water interface.

\section{Challenges in monitoring Groundwater- surface water interaction}

Some of the challenges in monitoring groundwater-surface water interaction are monitoring is difficulty of monitoring underwater, limitation in visual assessment of recharge or discharge, requirement of waterproof monitoring equipment, disturbance on monitoring equipments by humans and animals etc. Also, dynamic surface water environments results in movement of the equipment by storm or flood batteries that power equipment. Monitoring wells can be used to monitor subsurface environment, but many sites are accessible only by boat, which makes drilling wells impossible or expensive. Even in streams that are shallow, finding a platform for well installation can be difficult due to steep slopes or unstable ground and rocky streambed. The transient nature of the interface is another main challenge, ie, recharge and discharge areas can vary in time, so continuous data are needed to capture this variation. Recharge areas can become discharge areas and vice versa. There are number of different factors that make variations in time, from natural variation in precipitation to human induced alterations in land and water use. The impacts 
can be delayed, making the need for long term monitoring an additional challenge. To meet up these challenges, new techniques are to be developed to widen our understanding of the groundwater-surface water interface and to discover the complexities of our environment.

Research into groundwater-surface water interaction has also revealed heterogeneity that challenges our ability to make measurements at the appropriate scale. Despite these challenges, innovations in monitoring methods using geophysics, tracers, temperature, and remote sensing have provided new insights into spatial and temporal variation in groundwater-surface water interactions. Methods based on electrical, thermal, and physical properties of exchange zones can efficiently locate and quantify interactions between groundwater and surface water (USGS, 2019).

\section{In-situ monitoring of groundwater-surface water interaction}

Different in-situ monitoring methods include direct point measurement of fluxes, stream gauging, using temperature as a tracer of fluxes, geophysical monitoring, geochemical tracers etc. Direct point measurement of fluxes at the groundwater-surface water interface typically involves using Darcy's Law. Vertical gradient and hydraulic conductivity are obtained by installing wells. Measurements are made by collecting samples and analyzing in the lab or a field measurement such a slug testing. Limitation of this technique is the inaccuracy in calculating small head gradients and the difficulties in obtaining reliable hydraulic conductivity measurements. For point measurements at a slightly larger scale seepage meters are used, which consists of the cut-off top of a storage barrel that is pressed into a submerged sediment bed to separate seepage flow across a known surface area. A bag partially filled with water is attached to the barrel to record change in volume over time. Loss of water from the seepage bag records flux from the lake to groundwater, gain in water records flux from groundwater to the lake. Seepage meters have limitations of point measurements in that they may not predict heterogeneity well. But studies show that, increasing use of networks of seepage meters helps to reveal patterns in groundwater-surface water interaction. Schneider et al., (2005) instrumented the 88 $\mathrm{km}$ circumference of Oneida Lake in New York with 25 seepage meters, and found that discharge rates varied both spatially and temporally, but did not correlate with bed sediment texture. Toran et al., (2005) installed a network of 28 seepage meters along the southwest shore of Mirror Lake and found variations in discharge from 0 to $-282 \mathrm{~cm} / \mathrm{d}$.

Stream gauging is another common technique of estimating groundwater inflow to and outflow from streams. This method measures discharge along two cross sections and the difference in flow is attributed to groundwater input or stream loss. Some challenges associated with discharge measurements include finding appropriate reaches for accurate measurements and collecting data at high flow to determine relationships under dynamic conditions. High flow conditions and associated fast flowing water are dangerous for monitoring and errors associated with measurement of larger flows can be larger than the change in flow between gauging locations.

Usually the temperature of groundwater is different temperature from surface water. So, temperature can be used as a natural tracer of groundwater flux. Groundwater, with a steady temperature, tends to be cooler than surface water in the summer and warmer in the winter. Vertical temperature gradients can reveal rates of groundwater discharge. A 
distributed temperature system (DTS) is a technical innovation in temperature sensing which leverages the relationship between travel time of light and temperature in a fiber optic cable. Rayleigh, Brillouin and Raman scatterings in fibers result from the interaction of photons with local material characteristic features like density, temperature and strain. By detecting changes in the amplitude, frequency and phase of light scattered along a fiber, one can realize a distributed fiber sensor for measuring localized temperature, strain, vibration and birefringence over lengths ranging from meters to one hundred kilometers (Bao and Chen, 2012). Fiber-optic distributed temperature sensing (FO-DTS) is an emerging technology that has promise for characterizing estuary-aquifer and streamaquifer interaction and for identifying transmissive fractures in bedrock boreholes. The temperature of the water surface ("skin") can be evaluated remotely using thermal infrared (TIR) cameras. Because of inherent spatial scale and data collection efficiency trade-offs between different methods, several thermal methods are often used in concert (Hare et al., 2015).

Geophysics is a tool to understand heterogeneity at the groundwater-surface water interface as it provides continuous rather than point measurements. There are different types of geophysical techniques that can be applied at a variety of scales from airborne techniques for basin scale to hand held instruments that map a stream cross section.

Electrical resistivity is one of the most common geophysical monitoring methods, which measures the ease with which ions migrate between the two current electrodes. This technique has been applied to monitoring groundwater-surface water exchange in the ocean, in lakes, and in streams. Emerging hydro-geophysical tools and methods
(Electrical Resistivity Tomogaphy, Magnetic Resonance Sounding etc.) can improve our understanding of groundwater/surface-water exchange. These methods provide spatially distributed models of physical properties in regions that are difficult to sample using conventional hydro-geological borehole methods. It is therefore recommended to use more than one method to acquire a more unique signature of different geological units (Chirindja et al., 2016)

Geochemical tracers are also found to be useful in monitoring groundwater-surface water interaction. A geochemical tracer is found at high concentration in one component, such as groundwater, and can be used qualitatively or quantitatively. For example, radon-222 is found at higher concentration in groundwater than in surface water because it is volatile; its presence in streams, lakes, or the ocean is a signature of groundwater discharge (Toran, 2017).

In Conclusion monitoring and understanding of surface water groundwater interaction is a difficult and challenging task. But, with the development of new techniques understanding groundwater-surface water interaction is becoming easier. With the new techniques it is possible to know about spatial variation as well as temporal variation in fluxes. Fiber optic distributed temperature sensing systems (DTS), Geophysical methods, geochemical tracers etc., are some of the insitu monitoring methods for detecting groundwater-surface water interactions. Temperature sensing using fibre optic cables provide fine spatial and temporal resolution. These techniques can be used in combination also, which improves quality of monitoring and also helps in long term monitoring. These techniques in monitoring improves the data collection and provide input to models which will advance our understanding of the factors that influence fluxes and reveal dynamic 
responses of groundwater-surface water interaction.

\section{References}

Bao, X. and Chen, L. 2012. Recent Progress in Distributed Fiber Optic Sensors. Sensors 2012. 12: 8601-8639; doi:10.3390/s120708601.

Bruke, M., Gonser, T., 1997. The ecological significance of exchange processes between rivers and groundwater. Freshwater Biology. 37 (1): 460-47.

Chirindja, F. J., Dahlin, T., Perttu, N., Steinbruch, F., \& Owen, R. 2016. Combined electrical resistivity tomography and magnetic resonance sounding investigation of the surfacewater/groundwater interaction in the Urema Graben, Mozambique. Hydrogeology Journal. 24(6): 15831592.

Hare, D. K., Briggs, M. A., Rosenberry, D. O., Boutt, D. F., Lane, J. W. 2015. A comparison of thermal infrared to fiber-optic distributed temperature sensing for evaluation of groundwater discharge to surface water. Journal of Hydrology: 153-156.

Schneider, R. L., Negley, T. C., and Wafer, C. 2005. Factors influencing groundwater seepage in a large, ,mesotrophic lake in New York. Journal of hydrology. 310(1): 1-16

Toran, L., Nyquist, J.E., Rosenberry, D.O., Gagliano, M., Mitchell, $\mathrm{N}$ and Mikochik, J. 2015. Geophysical and hydrologic studies of lake seepage variability. Groundwater. 53(6), 841850.

Toran, L. 2017. Groundwater-Surface water interactions: A review for Encyclopedia of Water.

Toth, J. 1963. A theoretical analysis of groundwater flow in small drainage basins. 1963. Journal of Geophysical Research.68; 4785-4812.

USGS. 2019. Geophysics for USGS Groundwater/Surface Water Interaction Studies. https://www.usgs.gov.in (Accessed on 9/10/19)

Vaux, W.G. 1968. Intra-gravel flow and interchange of water in a streambed. Fish. Bull. 66: 479-489.

Winter, T.C.1976. Numerical Simulation Analysis of the Interaction of Lakes \& Groundwater. USGS Professional Paper 1001.

Winter, T.C., Harvey, J. W., Frank, O. L., and Alley, W. M. 1998. Ground Water and Surface Water: A Single Resource. U.S. Geological Survey Circular 1139.

Woessner, W.W. 2000. Stream and fluvial plain groundwater interactions: rescaling hydrogeological thought. Ground Water. 38 (3): 423-429.

Zektser, I. S. and Loaiciga, H. A. 1993. Groundwater fluxes in the global hydrologic cycle: past, present and future. Journal of Hydrology. 144(14): 405-427.

\section{How to cite this article:}

Mamatha Prabhakar. 2020. Groundwater- Surface Water Interaction, its Importance, In-situ Monitoring and Monitoring Challenges-An Overview. Int.J.Curr.Microbiol.App.Sci. 9(04): 627-632. doi: https://doi.org/10.20546/ijcmas.2020.904.076 